significant, among those treated with other non-TNFis (HR 2.4; 95\% Cl 0.9, 6.3; $\mathrm{p}=0.08$ ) compared with those treated with abatacept. Infection-related medical costs were lower for abatacept compared with other non-TNFis as shown in the table 1 .

Conclusions: In the real-world setting in the United States, pts treated with abatacept versus other tDMARDs tended to have a lower risk for infection-related hospitalisation and lower infection-related medical costs.

Disclosure of Interest: D. Paul Employee of: Bristol-Myers Squibb, L. McDonald Employee of: Bristol-Myers Squibb, A. Marshall Shareholder of: Bristol-Myers Squibb, Employee of: Bristol-Myers Squibb, T. Curtice Employee of: Bristol-Myers Squibb, M. Lingohr-Smith Grant/research support from: Bristol-Myers Squibb, Employee of: Novosys Health, B. Menges Grant/research support from: BristolMyers Squibb, Employee of: Novosys Health, J. Lin Grant/research support from: Bristol-Myers Squibb, Employee of: Novosys Health

DOI: 10.1136/annrheumdis-2018-eular.2323

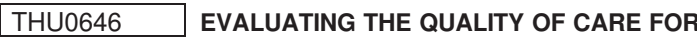 RHEUMATOID ARTHRITIS}

C. Barber ${ }^{1}$, D. Marshall ${ }^{1}$, E. Szefer ${ }^{2}$, D. Thompson ${ }^{2}$, D. Lacaille ${ }^{3} .{ }^{1}$ University of Calgary, Calgary; ${ }^{2}$ Emmes Canada; ${ }^{3}$ University of British Columbia, Vancouver, Canada

Background: The Arthritis Alliance of Canada (AAC) has developed performance measures (PMs) to evaluate RA care quality.

Objectives: To operationalize and report on 4 PMs using administrative data for British Columbia (BC), Canada: PM1) percentage of patients with new onset RA with at least one visit to a rheumatologist in the first year after diagnosis, PM2) percentage of RA patients under the care of a rheumatologist seen in follow-up at least once per year, PM3) percentage of RA patients dispensed a disease modifying anti-rheumatic drug (DMARD) during the measurement year, PM4) time to DMARD therapy in new onset RA.

Methods: All patients with RA visits between 01/01/1997 and 31/12/2009 in BC were identified using health administrative data and followed until December 2014. Cases were identified by $\geq 2$ physician billing codes for $R A \geq 8$ weeks but $\leq 5$ years apart. For this study, only cases age $>18$ who were seen by a rheumatologist at some point over follow-up were included. PM1: The percentage of incident RA cases with at least one visit to a rheumatologist within one year of their first RA visit was evaluated. PM2: The proportion of prevalent RA cases having at least one visit per year was calculated for those under rheumatology care. PM3: The percentage of prevalent RA patients dispensed a DMARD (including biologic agents and small molecule inhibitors) was calculated. PM4: time from RA onset (defined as first RA visit) to DMARD therapy was reported (in the calendar year of RA incidence), using median and 90th percentile wait time, as well as the proportion meeting the benchmark of 14 days.

Results: The cohort included 18976 incident and 29639 prevalent RA cases. The percentage of patients seen by a rheumatologist within 1 year from RA diagnosis increased over time, while the percentage of RA patients under the care of a rheumatologist seen in yearly follow-up declined steadily overtime. Further analysis (data not shown) suggests this is due to having more people with longer followup in the latter years, and lost to follow-up increasing over time, rather than a true calendar year effect. The percentage of RA patients dispensed a DMARD was suboptimal $(56 \%>65 \%)$. Of note, patients were not necessarily seen by a rheumatologist during the measurement year. The median time to DMARD improved over time to 23 days in 2009, with roughly one third receiving a DMARD within the benchmark of 14 days.

Conclusions: The present study represents the first time the AAC's PMs have been tested in administrative data and highlights where the measures are being met and potential gaps in care which require further examination.

Disclosure of Interest: None declared

DOI: 10.1136/annrheumdis-2018-eular.5023

\section{THU0647 LONGITUDINAL STUDY OF LONG-TERM POVERTY AND PERSISTENT DEPRESSIVE SYMPTOMS IN SLE}

E. Yelin ${ }^{1}$, J. Yazdany ${ }^{1}$, L. Trupin ${ }^{1}$, N. McCormick ${ }^{2}$, P. Katz ${ }^{1}$. 'Medicine/

Rheumatology, University of California, San Francisco, San Francisco, USA;

${ }^{2}$ Arthritis Research Centre of Canada, University of British Columbia, Vancouver, Canada

Background: A prior study found that persons with SLE in long-term poverty have greater accumulation of disease damage over 6 years than those exiting poverty or never in poverty ${ }^{1}$. The present study evaluates the effect of long-term poverty status on depressive symptoms over the same duration of time.

Objectives: Analyse the impact of long-term poverty on prevalent and incident persistent depression after accounting for other risk factors for depression among persons with SLE.

Methods: Data are from the UCSF Lupus Outcomes Study in which persons with SLE were recruited in 2003 throughout the U.S. and interviewed annually through 2015. In each year we characterised respondents' poverty status based on household income and family size and administered the CESD measure of depressive symptoms, defining a high level of depressive symptoms using a validated SLE specific cutpoint $(\geq 24)$ associated with a formal diagnosis of depression ${ }^{2}$. Prevalent persistent depression was defined as having high levels of depressive symp toms for $\geq 3$ years between 2009 and 2015. Incident persistent depression used the same criteria, measured only among those who had low levels of depressive symptoms between 2006 and 2009. Logistic regression was used to estimate the impact of being poor in every year from 2003-2009, permanently leaving poverty by 2009 , or never being poor on prevalent and incident persistent depression, with and without adjustment for gender, age, marital status, race/ethnicity, education, disease duration, extent of accumulated damage by 2009 using the Brief Index of Lupus Damage ${ }^{3}$, smoking status, and BMI.

Results: 535 persons with SLE were interviewed in each year from 2003 to 2015 (94\% female, 65\% non-Hispanic whites, mean age in 200350 years, range 20 83 , mean disease duration 17 years, range 1-51). Between 2003 and 2009, 81\% were never poor, $8 \%$ exited poverty, and $11 \%$ were poor in every year. 89 of the $535(16.6 \%)$ met the study definition of prevalent persistent depression; $23(7.4 \%)$ of the 312 free of high levels of depressive symptoms from 2006-2009 had incident persistent depression as of 2015. Table 1, below, indicates that those who were poor in every year had significantly higher rates of prevalent and incident persistent depression than those exiting poverty or never poor.

Abstract THU0646 - Table 1. Results of Four Performance Measures for RA.

\begin{tabular}{|c|c|c|c|c|c|c|c|}
\hline $\begin{array}{l}\text { Measurement } \\
\text { Year }^{1}\end{array}$ & $\begin{array}{l}\text { Prevalent } \\
\text { RA cases }\end{array}$ & $\begin{array}{l}\text { Incident } \\
\text { RA cases }\end{array}$ & $\begin{array}{l}\text { PM1: } \\
\text { Patients seeing rheumatologist } \\
\text { within } 1 \text { year of RA onset }\end{array}$ & $\begin{array}{l}\text { PM2:\% of Patients under rheum care } \\
\text { with yearly rheumatology visits }\end{array}$ & $\begin{array}{c}\text { PM3: } \\
\% \text { Patients } \\
\text { dispensed a } \\
\text { DMARD }\end{array}$ & $\begin{array}{c}\text { PM4: } \\
\text { Median } \\
\text { (90th percentile) } \\
\text { days to DMARD }\end{array}$ & $\begin{array}{c}\text { PM4: } \\
\% \text { with } \\
\text { DMARD } \\
\text { within } \\
\text { 14 days of } \\
\text { onset }\end{array}$ \\
\hline 2004 & 17472 & 1647 & $80 \%$ & $57 \%$ & $59 \%$ & 31 (825) & $27 \%$ \\
\hline 2005 & 19097 & 1614 & $82 \%$ & $56 \%$ & $60 \%$ & $26(579)$ & $30 \%$ \\
\hline 2006 & 20612 & 1704 & $85 \%$ & $54 \%$ & $60 \%$ & 23 (411) & $31 \%$ \\
\hline 2007 & 21764 & 1430 & $83 \%$ & $53 \%$ & $60 \%$ & 29 (399) & $28 \%$ \\
\hline 2008 & 22721 & 1305 & $86 \%$ & $50 \%$ & $60 \%$ & 26 (339) & $29 \%$ \\
\hline 2009 & 23386 & 921 & $92 \%$ & $49 \%$ & $61 \%$ & 23 (188) & $34 \%$ \\
\hline 2010 & 23122 & - & - & $46 \%$ & $60 \%$ & - & - \\
\hline 2011 & 22781 & - & - & $44 \%$ & $56 \%$ & - & - \\
\hline 2012 & 22370 & - & - & $42 \%$ & $56 \%$ & - & - \\
\hline 2013 & 21966 & - & - & $41 \%$ & $57 \%$ & - & - \\
\hline 2014 & 21412 & - & - & $41 \%$ & $57 \%$ & - & - \\
\hline
\end{tabular}

${ }^{1}$ PMs reported on a prevalent cohort until 2014, and on an incident cohort reported until 2009 
Abstract THU0647 - Table 1. Odds Ratios $(95 \% \mathrm{Cl}$ ) for Effect of Poverty Status between 2003 and 2009 on Prevalent and Incident Persistent Depression. CESD Score $\geq 24$ in 3 or More Years), between 2009 and 2015, with and without Adjustment

\begin{tabular}{l|l|l|l}
\hline Outcome & Poor Every Year & Exited Poverty & $\begin{array}{c}\text { Never } \\
\text { Poor }\end{array}$ \\
\hline $\begin{array}{l}\text { Prevalent Persistent Depression } \\
(n=535)\end{array}$ & & & \\
\hline Unadjusted & $3.9(2.1,7.2)^{*}$ & $1.0(0.4,2.2)$ & Ref. \\
\hline Adjusted $t$ & $2.9(1.4,6.1)^{*}$ & $0.8(0.3,1.8)$ & Ref. \\
\hline $\begin{array}{l}\text { Incident Persistent Depression } \\
(n=312) \ddagger\end{array}$ & & & \\
\hline Unadjusted & $4.5(1.3,15.4)^{*}$ & $0.9(0.2,3.9)$ & Ref. \\
\hline Adjusted $\dagger$ & $4.1(0.9,19.1)$ & $0.7(0.1,3.7)$ & Ref. \\
\hline
\end{tabular}

$* p<01$

† Adjusted for gender, age, marital status, race/ethnicity, education, disease

duration, extent of accumulated damage in 2009, smoking status, and BMI

‡ Excludes persons with high levels of depressive symptoms 2006-2009

Conclusions: Public policy to help persons with SLE stay out of poverty or to exit poverty may lower their rates of prevalent and incident persistent depression. Attention to the economic status of persons with SLE should be part of an overall treatment strategy including treatment for depression since such attention may help reduce accumulation of damage as well as reduce the prevalence and incidence of persistent depression.

\section{REFERENCES:}

11] Yelin E, et al. Arthritis rheumatol 2017;69:1612-1622.

[2] Julian L, et al. Arthritis care \& research 2011;63:884-890.

[3] Yazdany J, et al. Arthritis care \& research 2011;63:1170-1177.

Disclosure of Interest: E. Yelin Grant/research support from: Robert Wood Johnson Foundation Investigator in Health Policy Award, J. Yazdany: None declared, L. Trupin: None declared, N. McCormick: None declared, P. Katz: None declared

DOI: 10.1136/annrheumdis-2018-eular.2055

\section{THU0648 "AS A PRACTITIONER I FEEL ENRICHED”: RHEUMATOLOGY TUTORS' EXPERIENCES OF DELIVERING A MANUALISED GROUP COGNITIVE- BEHAVIOURAL FATIGUE PROGRAMME TO PATIENTS WITH RHEUMATOID ARTHRITIS (RA)}

E. Dures ${ }^{1}$, A. Hammond ${ }^{2}$, S. Hewlett ${ }^{1}$, on behalf of The RAFT Group. ${ }^{1}$ School of Health Sciences, University of the West of England, Bristol, Bristol; ${ }^{2}$ School of Health Sciences, University of Salford, Salford, UK

Background: Reducing Arthritis Fatigue by clinical Teams using cognitivebehavioural approaches (RAFT) is a 7-centre RCT of a manualised group cognitive-behavioural (CB) programme to reduce fatigue impact. ${ }^{1}$ After four days training plus a delivery observed by clinical supervisors, tutor pairs (rheumatology nurses and occupational therapists (OTs)) delivered the programme four times to patients with RA. Quality assurance observations confirmed tutors used CB approaches and RAFT results show the programme reduced patients' fatigue impact at 26 weeks. ${ }^{2}$

Objectives: The aim of the current study was to understand tutors' experiences of RAFT training and delivery to inform future programme roll out.

Methods: 14 RAFT tutors (9 nurses; 5 OTs) participated in one-to-one interviews, which were audio-recorded and transcribed. Data were analysed by ED, SH, and $\mathrm{AH}$ using inductive thematic analysis.

Results: Four main themes were identified.

Theme 1: "It's quite daunting" - Delivering a complex programme that was "quite different to what any of us had done before" required time and effort ("I couldn't really make sense of it without actually doing a lot of work around it"). Initially, training with clinical supervisors ("experts") who are "so good at what they do" challenged tutors' confidence ("the anxiety is are we going to deliver it the way they did?").

Theme 2: "Most useful was actually getting to practice the sessions" - Tutors valued watching clinical supervisors demonstrate programme sessions during training ("professionals who have shown us how to do it") plus the opportunity to practice themselves ("role playing the sessions was really helpful").

Theme 3: "Putting it in a way that was still true to the message" - The RAFT manual was "very valuable" and "it had to be adhered to"; however, tutors wrote individual crib notes ("our own manual in our own words") to consolidate information, deepen understanding, and gain confidence. The process was supported by "positive and constructive criticism" in the observed delivery ("the supervisor kept putting us back on track").

Theme 4: "As a practitioner I feel enriched" - CB skills acquired during RAFT impacted tutors' wider work ("making a massive difference to my clinical practice"), and enhanced the self-management support they offered patients, including "the particular ability to draw things out from people" and "learning when to listen and stand back and try and get the patients to find the answers".

Conclusions: Initially, RAFT training and delivery were a challenge for tutors because the $\mathrm{CB}$ approach was a new way of working. Individually adapting RAFT manual wording plus feedback from supervisors increased tutors' confidence. Tutors believed the CB skills acquired during RAFT enhanced their wider clinica practice and the self-management support they offered patients. Future training should include RAFT session demonstrations and skills practice for tutors, with feedback from clinical supervisors.

\section{REFERENCES:}

[1] Hewlett, et al. A randomised controlled trial for Reducing Arthritis Fatigue by clinical Teams using cognitive behavioural approaches (RAFT). BM Open 2015;5:e009061.

[2] Hewlett, et al. OP0139-HPR Reducing Arthritis Fatigue: Clinical Teams (RAFT) using Cognitive-Behavioural Approaches: an RCT. Annals of the Rheumatic Diseases 2017;76:110.

Disclosure of Interest: None declared

DOI: 10.1136/annrheumdis-2018-eular.1126

\section{THU0649 UNDERSTANDING ETHNIC DIFFERENCES IN THE UTILISATION OF EXERCISE FOR OSTEOARTHRITIS}

E.R. Vina ${ }^{1}$, D. Ran ${ }^{2}$, M.J. Hannon ${ }^{3}$, C.K. Kwoh ${ }^{1} .{ }^{1}$ Division Rheumatology, Medicine; ${ }^{2}$ Arthritis Center, University of Arizona, Tucson; ${ }^{3}$ Medicine, University of Pittsburgh, Pittsburgh, USA

Background: According to a US survey, the prevalence of arthritis-attributable activity limitation, work limitation and severe pain are all significantly higher among Hispanics than among non-Hispanics (NHs). Ethnic differences in osteoarthritis (OA) patients' experience of pain may be related to marked disparities in the use of OA treatments. According to EULAR OA guidelines, exercise should be an integral part of the management of knee and hip OA. Whether or not exercise is underutilised and why it may be underutilised by Hispanics to treat $O A$ is unclear. Objectives: The objective of this study was to determine if there are ethnic differences in the history and current use of exercise as therapy for patients with knee or hip OA. The secondary objective was to compare Hispanic and $\mathrm{NH}$ patients with lower extremity $\mathrm{OA}$ with respect to their familiarity and perceptions of the efficacy and risk of exercise as treatment for $O A$.

Methods: Research participants $>50$ years of age with chronic and frequent pain due to knee or hip OA were recruited from a university medical centre. Structured interviews were conducted to determine patient sociodemographic characteris tics, clinical information, self-reported actual use/prescription receipt of exercise for OA treatment (currently, last 5 years), and familiarity with exercise (3 items, yes/no response). Perceptions of the benefits ( 4 items) and risks ( 3 items) of exercise, and willingness to exercise to treat $O A$ were also evaluated; each question in these measures has a five-category ordinal response scale. Fisher's exact or Wilcoxon-Mann-Whitney tests were conducted to determine if knowledge and perceptions about exercise were associated with ethnicity (Hispanic vs NH).

Results: In our cohort of patients with knee or hip OA, Hispanics $(n=119)$, in comparison to $\mathrm{NHs}(\mathrm{n}=201)$, were younger (mean age 61.5 vs. 65.3 ) and less likely to have an annual income of $>\$ 50,000$ (13.5\% vs. $39.1 \%$ ). A lower proportion of Hispanics than $\mathrm{NHs}$ reported using exercise to treat $\mathrm{OA}$ at present $(51 \%$ vs. $66 \%$, $p=0.0165)$ and in the last five years $(68 \%$ vs. $84 \%, p=0.0010)$ or receiving a prescription for exercise in the last five years (45\% vs. $67 \%, \mathrm{p}<0.0001)$ (figure 1). Hispanics, compared to $\mathrm{NHs}$, were also less likely to report ever hearing about exercise to treat OA $(71.43 \%$ vs. $91.83 \%, p<0.0001)$, having family/friends that received it for treatment $(33.33 \%$ vs. $51.20 \%, p=0.0023)$, or having a good understanding of it as a treatment for OA $(66.96 \%$ vs. $79.33 \%, p=0.0161)$. A lower proportion of Hispanics than $\mathrm{NHs}$ believe that exercise is beneficial (or very beneficial) for arthritis $(49.12 \%$ vs. $69.09 \%, p<0.0001)$ and that exercise is helpfu (or very helpful) for them (60.52\% vs. $75.61 \%, p=0.0056)$. No ethnic differences in the perceptions of risk of exercise were observed. Hispanics were also less willing to exercise to treat $\mathrm{OA}$ than $\mathrm{NHs}(67.83 \%$ vs. $82.61 \%, \mathrm{p}=0.0018)$.

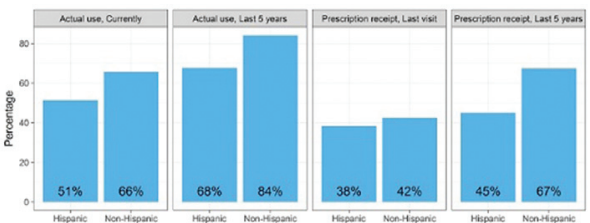

Abstract THU0649 - Figure 1 Proportion. who reported use of or prescription receipt for exercise to treat $O A$ by ethnicityConclusions: Among patients with knee or hip OA, Hispanics were less likely than $\mathrm{NHs}$ to utilise exercise as treatment for arthritis. 